\title{
Left Ventricular Thrombus Formation in Acute Anterior Wall Myocardial Infarction: A Comparison Between Thrombolyzed and Non- Thrombolyzed Patients
}

\author{
Kashif A. Hashmi ${ }^{1}$, Hadi Y. Saeed ${ }^{1}$, Jawad Ahmed ${ }^{1}$, Javeria Najam ${ }^{2}$, Muhammad Irfan ${ }^{3}$, Atif A. Hashmi ${ }^{4}$ \\ 1. Cardiology, Chaudhry Pervaiz Elahi Institute of Cardiology, Multan, PAK 2. Medicine, Liaquat National Hospital and \\ Medical College, Karachi, PAK 3. Statistics, Liaquat National Hospital and Medical College, Karachi, PAK 4. Pathology, \\ Liaquat National Hospital and Medical College, Karachi, PAK
}

Corresponding author: Atif A. Hashmi, atifhashmi345@gmail.com

\section{Abstract \\ Introduction}

Left ventricular thrombus (LVT) formation is a prominent complication of acute myocardial infarction (AMI). Accurate and prompt detection of the condition is important as it poses a high risk for thromboembolic events that can be arrested by systemic anticoagulation. The purpose of our study was to evaluate the frequency of LVT formation in thrombolyzed and non-thrombolyzed patients with AMI to ascertain the current magnitude of the problem in the local population.

\section{Methods}

The study was conducted at the Chaudhry Pervaiz Elahi Institute of Cardiology in Multan, Pakistan. A total of 281 patients of either gender aged between 30-65 years with anterior wall myocardial infarction (AWMI; both thrombolyzed and non-thrombolyzed) were included in the study. Once they were enrolled in the study, all the relevant baseline investigations were performed. A detailed history was taken and examinations were done; serial ECG and echocardiography were performed till discharge from the hospital on the third day of hospitalization to record the final outcome of the study, i.e., LVT formation.

\section{Results}

The mean age of the patients was $55.54 \pm 7.26$ years. Overall, LVT formation was noted in 65 cases $(23.1 \%)$, of which 11 (16.9\%) were thrombolyzed patients and 54 (83.1.1\%) were non-thrombolyzed. A significant association of LVT was noted with age, hypertension, family history, and duration of symptoms.

\section{Conclusion}

Received 06/22/2020 Review began 06/26/2020 Review ended 06/27/2020 Published 07/09/2020

\section{๑) Copyright 2020}

Hashmi et al. This is an open access article distributed under the terms of the Creative Commons Attribution License CC-BY 4.0., which permits unrestricted use, distribution, and reproduction in any medium, provided the original author and source are credited.
We found a high frequency of LVT formation among patients with AWMI who have not undergone thrombolytic therapy. It was observed that LVT was notably associated with advanced age, hypertension, and other comorbidities. Early presentation to the hospital and thrombolysis reduce the risk of developing LVT, which in turn can reduce morbidity and mortality in such patients.

\footnotetext{
Categories: Cardiology

Keywords: left ventricular thrombosis, anterior wall acute myocardial infarction, thrombolytic therapy
}

\section{Introduction}

Ischemic heart disease (IHD) is a major cause of morbidity and mortality worldwide [1-3]. Males are more commonly affected by this condition than females. Atherosclerotic coronary artery disease (CAD) causing myocardial ischemia may manifest itself either as acute myocardial infarction (AMI), unstable angina, or effort angina. Among these, AMI is the most predominant life-threatening disease usually encountered in emergency hospital admissions. The mortality rate for AMI has decreased by about 30\% over the last two decades, but it still remains high, especially in underdeveloped countries. The cardiovascular comorbidities associated with AMI are on the rise in Pakistan where 18\% of the adult population suffers from hypertension, tobacco addiction, and obesity.

Left ventricular thrombus (LVT) is a blood clot that forms in the left ventricle of heart due to stasis of blood. LVT leading to cerebrovascular accidents is a potentially catastrophic complication following anterior STsegment elevation myocardial infarction (STEMI) [4]. Although anticoagulation is often prescribed for this, data regarding the appropriate drug, duration, risks, and effect on echocardiographic indices of thrombus are lacking. Moreover, given the difficulty in obtaining adequate anticoagulation with warfarin, it is possible that short-term treatment with a more predictable agent would be more effective $[5,6]$. Acute 
thromboembolic events due to LVT formation, particularly in patients with reduced ejection fraction (EF), remain a risk for patients surviving anterior STEMI. The reported incidence of LVT formation and subsequent embolization varies based on the timing of the echocardiographic examination and the diagnosis, anticoagulation, and reperfusion strategies utilized in managing the initial presentation. However, it is estimated to range from 0 to as high as $86 \%$ [7,8]. A study conducted by Zia et al. has reported LVT formation in $15.4 \%$ of patients with anterior wall acute myocardial infarction (AWMI). While LVT was found in $5.4 \%$ of the patients thrombolyzed with streptokinase, it was present in $30.4 \%$ of those who were not thrombolyzed [9].

The purpose of our study was to evaluate the frequency of LVT formation in thrombolyzed and nonthrombolyzed patients with AMI to ascertain the current magnitude of the problem in the local population. We believe that the results of this study will help clinicians to anticipate LVT among the targeted population and treat them accordingly. We also feel that the study provides useful baseline information on this topic and highlights the importance of thrombolytic therapy in AMI patients, which will contribute to improving clinical outcomes in these patients. Finally, we think our findings will improve the quality of life of the patients and will also help reduce hospital costs, which will be beneficial for national health economies.

\section{Materials And Methods}

This descriptive study was conducted at the Department of Cardiology, Chaudhry Pervaiz Elahi Institute of Cardiology in Multan, Pakistan. We conducted the study after obtaining approval from the institute's Ethical Review Committee. A total of 281 patients of either gender aged between 30-65 years with AWMI (both thrombolyzed and non-thrombolyzed) were included in the study based on consecutive sampling over a period of one year. Informed consent was taken from the patients/attendants of patients after explaining the objectives of this study, ensuring the confidentiality of the information provided, and providing assurance that the patients were in no danger due to participating in this research. Once they were enrolled in the study, all the relevant baseline investigations were performed. A detailed history was taken and examinations were done; serial ECG and echocardiography were performed till discharge from the hospital on the third day of hospitalization to record the final outcome of the study, i.e., LVT formation. All the data was recorded on a predesigned proforma.

\section{Statistical analysis}

All the data was entered and analyzed using IBM SPSS Statistics for Windows, Version 20.0 (IBM, Armonk, $\mathrm{NY}$ ). Descriptive statistics were applied to calculate the mean and standard deviation for the age of the patients and the duration of symptoms. Frequencies and percentages were compiled for categorical variables. The frequency of LVT was compared between thrombolyzed and non-thrombolyzed patients by applying the chi-square test at a level of significance of 0.05 . Effect modifiers like age and diabetes were controlled by preparing stratified charts. The post-stratification chi-square test was applied to see its effect on outcomes. A p-value of $\leqslant 0.05$ was considered to be statistically significant.

\section{Results}

Our study comprised a total of 281 patients who met the inclusion criteria. Of the 281 patients, 184 (65.5\%) were male and 97 (34.5\%) were female. The mean age of the patients was $55.54 \pm 7.26$ years (range: $40-65$ years). Most of the patients (204, 72.6\%) were more than 50 years of age. Of the 281 patients, 106 (37.7\%) belonged to rural areas and 175 (62.3\%) belonged to urban areas. Diabetes was present in 87 (31\%) subjects, hypertension in 130 (46.3\%), and 65 (23.1\%) had a history of smoking. The mean duration of symptoms was $7.25 \pm 3.82$ hours, and 151 (53.7\%) patients had a duration of symptoms for more than six hours. Family history was positive in 106 (37.7\%), while thrombolytic therapy was given for 194 (69.0\%) of our study cases. LVT formation was noted in 65 (23.1\%) cases, of which 11 (16.9\%) were thrombolyzed patients and 54 (83.1\%) non-thrombolyzed. The characteristics of the study population are presented in Table 1. 


\section{Cureus}

Characteristic

N (\%)

Gender

Male

184 (65.5)

Female

97 (34.5)

Age group

$\leq 50$ years

$>50$ years

Residence

Rural

$106(37.7)$

Urban

Diabetes mellitus

Present

$87(31)$

Absent

Hypertension

Present

$130(46.3)$

Absent

Smoking

Present

Absent

Duration of symptoms

$\leq 6$ hours

$>6$ hours

151 (53.7)

Family history of Ischemic heart disease

Present

106 (37.7)

Absent

175 (62.3)

Thrombolytic therapy

Given

$194(69)$

Not given

87 (31)

Left ventricular thrombus formation

Present

$65(23.1)$

Absent
216 (76.9)

\section{TABLE 1: Characteristics of the study population}

Our results showed a significant association of LVT formation with age $(\mathrm{p}=0.039)$, hypertension $(\mathrm{p}$ : $<0.001)$, symptoms duration (p: <0.01), family history of IHD, and thrombolytic therapy (p: <0.001), as presented in Table 2 . 


\section{Cureus}

\begin{tabular}{|c|c|c|c|}
\hline \multirow[t]{2}{*}{ Characteristic } & \multicolumn{2}{|l|}{$\mathrm{N}(\%)$} & \multirow{2}{*}{ P-value } \\
\hline & Present & Absent & \\
\hline \multicolumn{4}{|l|}{ Gender } \\
\hline Male & $44(67.7)$ & $140(64.8)$ & \multirow{2}{*}{$0.766^{\star \star}$} \\
\hline Female & $21(32.3)$ & 76 (35.2) & \\
\hline \multicolumn{4}{|l|}{ Age group } \\
\hline$\leq 50$ years & $11(16.9)$ & 66 (30.6) & \multirow{2}{*}{$0.039^{\star}$} \\
\hline$>50$ years & $54(83.1)$ & $150(69.4)$ & \\
\hline \multicolumn{4}{|l|}{ Residence } \\
\hline Rural & $21(32.3)$ & $85(39.4)$ & \multirow{2}{*}{$0.381^{\star *}$} \\
\hline Urban & $44(67.7)$ & $131(60.6)$ & \\
\hline \multicolumn{4}{|c|}{ Diabetes mellitus } \\
\hline Present & $22(33.8)$ & $65(30)$ & \multirow{2}{*}{$0.646^{\star \star}$} \\
\hline Absent & $43(66.2)$ & $151(70)$ & \\
\hline \multicolumn{4}{|l|}{ Hypertension } \\
\hline Present & $43(66.1)$ & $87(40.3)$ & \multirow{2}{*}{$<0.001^{*}$} \\
\hline Absent & $22(33.9)$ & $129(59.7)$ & \\
\hline \multicolumn{4}{|l|}{ Smoking } \\
\hline Present & $11(16.9)$ & $54(25)$ & \multirow{2}{*}{$0.240^{\star \star}$} \\
\hline Absent & 54 (83.1) & $162(75)$ & \\
\hline \multicolumn{4}{|c|}{ Duration of symptoms } \\
\hline$\leq 6$ hours & $11(16.9)$ & $119(55.1)$ & \multirow{2}{*}{$<0.001^{*}$} \\
\hline$>6$ hours & $54(83.1)$ & $97(44.9)$ & \\
\hline \multicolumn{3}{|c|}{ Family history of Ischemic heart disease } & \\
\hline Present & $10(15.4)$ & $96(44.4)$ & \multirow{2}{*}{$<0.001^{*}$} \\
\hline Absent & $55(84.6)$ & $120(55.6)$ & \\
\hline \multicolumn{4}{|c|}{ Thrombolytic therapy } \\
\hline Given & $11(16.9)$ & $183(84.7)$ & \multirow{2}{*}{$<0.001^{\star}$} \\
\hline Not given & $54(83.1)$ & $33(15.3)$ & \\
\hline
\end{tabular}

\section{TABLE 2: Association of left ventricular thrombus formation with clinical features and}

comorbidities

Chi-square test was applied; $p$-value of $\leq 0.05$ considered statistically significant

${ }^{*}$ P-value significant

**P-value not significant

\section{Discussion}

LVT is a known sequel of AMI owing to stasis of blood over damaged heart muscles, which can lead to systemic embolization resulting in a stroke. Early reperfusion is the most effective treatment modality in such circumstances while therapeutic anticoagulation is useful in preventing the risk of thrombosis and 
embolization [10].

We found LVT formation in 65 (23.1\%) of our study subjects, of which 11 (16.9\%) were thrombolyzed patients while 54 (83.1\%) were non-thrombolyzed. Our findings vary slightly from those of other loco-regional studies. A study conducted by Zia et al. has reported an LVT incidence of $15.4 \%$ in patients with AWMI. While LVT was found in $5.4 \%$ of the patients thrombolyzed with streptokinase, it was present in $30.4 \%$ of those who were not thrombolyzed [9]. Another study from Norway by Solheim et al. has reported similar results, showing a high prevalence of LVT in non-thrombolyzed patients [11].

We found a male predominance (65.9\%) in our studied patient population. The male predominance with respect to AMI has been well documented in the literature. Loco-regional literature has shown male gender predominance ranging from $65 \%$ to as high as $80 \%$ in a few studies $[9,12,13]$. Our study results were consistent with these findings.

The mean duration of symptoms was $7.25 \pm 3.82$ hours, and 151 (53.7\%) patients had a duration of symptoms for more than six hours. Family history was positive in 106 (37.7\%), while thrombolytic therapy was given for 194 (69.0\%) of our study cases. The mean age of the patients was $55.54 \pm 7.26$ years (range: $40-65$ years). The mean age of the male patients was noted to be $55.51 \pm 8.22$ years, while that of female patients was $55.60 \pm$ 4.98 years $(\mathrm{p}=0.924)$. Most of the patients $(204,72.6 \%)$ were more than 50 years of age. The mean age in other regional studies was reported to range from 53 to 55 years $[9,12,13]$, which was consistent with our data.

Our study has a few limitations. Firstly, this was a single-institution study; however, the institute has a high influx of patients from both the rural and urban areas, and hence the patient population was quite representative of the country's general population. Secondly, we did not engage in a long-term follow-up of the patients to evaluate other long-term complications of AMI in the studied population.

\section{Conclusions}

In our study, we found a high frequency of LVT formation among patients with AWMI who have not undergone thrombolytic therapy. We also observed a significant association of LVT with advanced age, hypertension, and other comorbidities. Early presentation to the hospital and thrombolysis reduce the risk of developing LVT, which in turn can bring down morbidity and mortality in such patients.

\section{Additional Information \\ Disclosures}

Human subjects: Consent was obtained by all participants in this study. Ethical Review Committee of Chaudhry Pervaiz Elahi Institute of Cardiology, Multan issued approval 35. This study was approved by the Ethical Review Committee of Chaudhry Pervaiz Elahi Institute of Cardiology. Animal subjects: All authors have confirmed that this study did not involve animal subjects or tissue. Conflicts of interest: In compliance with the ICMJE uniform disclosure form, all authors declare the following: Payment/services info: All authors have declared that no financial support was received from any organization for the submitted work. Financial relationships: All authors have declared that they have no financial relationships at present or within the previous three years with any organizations that might have an interest in the submitted work. Other relationships: All authors have declared that there are no other relationships or activities that could appear to have influenced the submitted work.

\section{References}

1. Finegold JA, Asaria P, Francis DP: Mortality from ischaemic heart disease by country, region, and age: statistics from World Health Organisation and United Nations. Int J Cardiol. 2013, 168:934-45. 10.1016/j.ijcard.2012.10.046

2. Nowbar AN, Howard JP, Finegold JA, Asaria P, Francis DP: 2014 global geographic analysis of mortality from ischaemic heart disease by country, age and income: statistics from World Health Organisation and United Nations. Int J Cardiol. 2014, 174:293-8. 10.1016/j.ijcard.2014.04.096

3. Moran AE, Forouzanfar MH, Roth GA, Mensah GA, Ezzati M, Murray CJ, Naghavi M: Temporal trends in ischemic heart disease mortality in 21 world regions, 1980 to 2010: the Global Burden of Disease 2010 study. Circulation. 2014, 129:1483-92. 10.1161/CIRCULATIONAHA.113.004042

4. White DC, Grines CL, Grines LL, Marcovitz P, Messenger J, Schreiber T: Comparison of the usefulness of enoxaparin versus warfarin for prevention of left ventricular mural thrombus after anterior wall acute myocardial infarction. Am J Cardiol. 2015, 115:1200-3. 10.1016/j.amjcard.2015.02.007

5. Driesman A, Hyder O, Lang C, Stockwell P, Poppas A, Abbott JD: Incidence and predictors of left ventricular thrombus after primary percutaneous coronary intervention for anterior ST-segment elevation myocardial infarction. Clin Cardiol. 2015, 38:590-7. 10.1002/clc.22450

6. Le May MR, Acharya S, Wells GA, et al.: Prophylactic warfarin therapy after primary percutaneous coronary intervention for anterior ST-segment elevation myocardial infarction. JACC Cardiovasc Interv. 2015, 8:15562. 10.1016/j.jcin.2014.07.018

7. Schwalm JD, Ahmad M, Eikelboom JW, Natarajan MK: A national survey of Canadian practice patterns of warfarin after anterior wall myocardial infarction in the current era of dual antiplatelet therapy. Am J 


\section{Cureus}

Cardiol. 2010, 105:1844. 10.1016/j.amjcard.2010.03.022

8. Oyetayo OO, Slicker K, De La Rosa L, et al.: Dual antiplatelet compared to triple antithrombotic therapy in anterior wall acute myocardial infarction complicated by depressed left ventricular ejection fraction. Proc (Bayl Univ Med Cent). 2015, 28:445-9. 10.1080/08998280.2015.11929303

9. Zia S, Hussain S, Farogh A: Frequency of left ventricular thrombus formation after acute anterior wall ST elevation myocardial infarction. Pak Heart J. 2014, 47:169-74.

10. Stokman PJ, Nandra CS, Asinger RW: Left ventricular thrombus. Curr Treat Options Cardiovasc Med. 2001, 3:515-21. 10.1007/s11936-001-0025-6

11. Solheim S, Seljeflot I, Lunde K, Bjørnerheim R, Aakhus S, Forfang K, Arnesen H: Frequency of left ventricular thrombus in patients with anterior wall acute myocardial infarction treated with percutaneous coronary intervention and dual antiplatelet therapy. Am J Cardiol. 2010, 106:1197-200. 10.1016/i.amjcard.2010.06.043

12. Umar H, Mattiullah K, Nasir Hussain SK, et al.: Frequency of newly diagnosed diabetes mellitus in patients with acute myocardial infarction. J Ayub Med Coll Abbottabad. 2014, 26:368-70.

13. Malik MA, Alam Khan S, Safdar S, Taseer IU: Chest pain as a presenting complaint in patients with acute myocardial infarction (AMI). Pak J Med Sci. 2013, 29:565-8. 10.12669/pjms.292.2921 